\title{
Investigating effective factors on multimedia advertising: A case study of travel agencies
}

\author{
Naser Azad $^{\mathrm{a}^{*}}$, Seyed Mohsen Seyed Aliakbar ${ }^{\mathrm{a}}$ and Navab Kordalivand ${ }^{\mathrm{b}}$
}

${ }^{a}$ Department of Management, Islamic Azad University, South Tehran Branch, Tehran, Iran ${ }^{b}$ Department of Management, PayamNoor University, ShahreRey branch, ShahreRey, Iran

\begin{tabular}{l}
\hline A R T I C L E I N F O \\
\hline Article history: \\
Received March 1, 2011 \\
Received in Revised form \\
July, 14, 2011 \\
Accepted 15 July 2011 \\
Available online \\
20 July 2011 \\
\hline Keywords: \\
Media Advertisement \\
Travel agencies \\
Effectiveness \\
Effective parameters
\end{tabular}

\section{A B S T R A C T}

\begin{abstract}
Advertisement plays an important role on increasing sales and organizations normally spend significant amount of cost in an attempt to increase profitability. A productive advertisement normally involves various factors and we need to determine the most important ones, very carefully. In this paper, we use a questionnaire-based survey to find the most important factors influencing advertisement. In this paper, we focus on gathering information from the advertisement providers to assess each advertisement plan. The proposed study of this paper uses factor analysis to determine 15 most important factors, which include 42 variables.
\end{abstract}

\section{Introduction}

The new millennium promises us new and exciting technologies, which help business industries, provide their products and services through different advertisement channels. Chuang and Chong (2004) explained that a good advertisement must choose appropriate perspectives in terms of color, dimension and the content to affect end line customers, profoundly. Hawkins (2007) named two factors of color and motion as the most important factors influencing customer's attraction. He believed that bright colors and moving objects have more influencing in people's mind and they keep a good memory in their mind for a longer time.Typically web advertisers use two methods to measure the cost effectiveness of their web advertising: adviews and clickthroughs (Harvey, 1997). There are other important factors influencing customer attraction such as age. Older people better like and recall emotional than rational appeals, whereas younger adults better like and recall rational than emotional appeals together (McKay-Nesbitt et al., 2011). This suggests that, under low-involvement conditions, emotionally-framed appeals tend to be more effective than rationally-framed ones, especially for

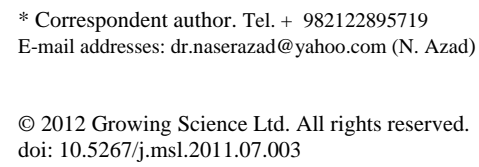


older than younger adults. The amount of time an advertisement attracts people is another important factors.

Hawkins (2007) explained that the longer an advertisement stays on people's mind, the longer they forget about the advertisement. Wu (2001) explained that one necessary condition for being a caring advertiser is to consider the cultural peculiarities of the foreign markets they are targeting. In other words, we need to learn more about the target market's culture and establish empathy with their experiences and beliefs. Adaptation of advertising prepared for their home-markets just by translating the verbal appeals into the languages of their host markets will most likely fail (Shavitt et al., 1993). Another necessary condition of efficient advertisement is to use pre-testing of visual and verbal contents of advertising prepared for foreign markets. Personal involvement is another important factor in advertisement. Wang (2009) explained that the effectiveness of cross-channel integration of advertising depends on consumers' levels of personal involvement. Education is another factor, which plays an important role in some events. Sirvastava (2010) explained that a highly educated person more likely to buy a product when he/she is logically justified about a product or service's characteristics. In other words, when consumers believe advertising is trustworthy and credible, they are more likely to accept the advertised product's claims and are more likely to change their attitudes and buying behavior.

The strong correlation between physical attractiveness and purchase intention support the belief that it is effective to sell a product using physically attractive models or product endorsers. The results also indicate that participants are more receptive towards complementary pictorial and verbal content featured in advertisements for purchase intention (Phau \& Lum ,2000). Codaccioni and Tafani (2011) studied the effect of the frequency of advertisement on increasing sales. They performed different experiments where the first experiment demonstrated that an advertisement's numerical support impacts its efficiency. Their study highlighted the fact that minority support for commercial advertisements can guarantee relatively greater efficiency, which translates here as latent influence, on the basis of which targets begin to elaborate upon source opinions, enhancing the attributes of the promoted product and improving attitudes towards it. James and Kover (1992), Mehta (2000) and Wang (2009) also investigated whether overall attitudes toward advertising affect involvement with specific advertisements or not.

Chowdhury et al. (2011) investigated the number of advertisements for effectively penetrating to the market. They showed that for advertisement with univalenced images, advertisers should select one image that has the requisite affective valence and intensity and provides a clear example of the benefit being advertised. When advertisements use oppositely valenced images a higher number of positive or negative pictures can generate greater affective response. Jeon and Beatty (2002) studied comparative advertising effectiveness in different national cultures. Liu et al. (2009) addressed consumer responses to sex appeal advertising for a cross-cultural study. They examined the effect of sex appeal on ad and brand evaluation among Australian, Chinese and US consumers and found that Australian, Chinese and US consumers had significantly different attitudes when exposed to the same advertisement but consumer buying intentions towards the advertised brand were not substantially different.

Patsioura et al. (2009) presented an effectiveness conceptual framework for the assessment of the overall performance of corporate advertising web sites towards the multiple advertising, promotional and relationship marketing objectives of their establishment. They examined communication, feedback and customer support policies to identify their contribution in creating or influencing advertising "effects”. Their Findings disclosed the significant dimensions of the participants' behavior based on their actions, activities, preferences and intentions. Phau and Teah (2009) examined young consumers' motives for using short message service (SMS), their SMS usage frequency, and their attitudes towards SMS advertising. They used Factor analysis on the motives for using SMS, discovered seven factors, and showed that convenience and economical reasons influence SMS usage 
frequency. Lee-Wingate and Xie, (2010) investigated consumer perceptions of product-claim versus help-seeking direct-to-consumer advertising (DTCA) and reported that consumers perceived helpseeking DTCA as being highly informative without persuasive intent, whereas they perceived product-claim DTCA as having high-persuasive intent with little informativeness.

During the past few years, internet advertisement has played an important role on selling products and services through digital world (Brett, 2002). Baltas (2003) performed an empirical study to find important factors in this type of business.

The organization of this paper first presents the details of our proposed study in section 2 and the results are discussed in section 3. Finally, conclusion remarks are given in the last to summarize the contribution of this paper.

\section{The proposed study}

The proposed study of this paper designs a questionnaire for travel agencies located in Tehran/Iran, which consists of 57 questions based on Likert scale. We have chosen three quetionnaire for every question and the number of sample size is calculated as $n=171$. We have distributed 178 questionnaires among the population of our survey, which are different travel agencies. We use Factor analysis to study the behavior of the data (Brace et al., 2006) and the Cronbach alpha (1951) was calculated as $70 \%$. Since Factor analysis is very sensitive against skewness ratio we decided to remove questions 9-14, 19, 23, 40, 45 and 47-51. Then we have determined 15 factors including 42 variables. Each factor consists of 2, 3 or 4 variables. Next, we explain each factor and its variables in details.

\section{Details of Factor analysis}

\subsection{The concept of naming}

This concept consists of four variables of convincible concept, concept, content and perception. Table 1 shows the details of our analysis where Cronbach alpha (1951) is 71\%.

\section{Table 1}

Factor analysis for concept of advertisement

\begin{tabular}{lllll}
\hline Option & Factor weight & Eigen value & \% of variance & Accumulated \\
\hline Convincible concept & 0.807 & & & \\
Concept & 0.769 & 4.446 & 10.585 & 10.585 \\
Content & 0.756 & & & \\
Perception & 0.371 & & & \\
\hline
\end{tabular}

\subsection{Theological concepts}

The second factor is theological concepts, which consists of three variables of pretest theological concepts, pretest visual concepts and theological concepts. Table 2 demonstrates the details of our analysis where Cronbach alpha (1951) is 73\%.

\section{Table 2}

Factor analysis for theological concepts of advertisement

\begin{tabular}{lllll}
\hline Option & Factor weight & Eigen value & \% of variance & Accumulated \\
\hline $\begin{array}{l}\text { Pretest theological } \\
\text { concepts }\end{array}$ & 0.856 & & & \\
$\begin{array}{l}\text { Pretest visual concepts } \\
\text { Theological concepts }\end{array}$ & 0.842 & 2.448 & 5.829 & 16.413 \\
\hline
\end{tabular}




\subsection{Presence on website}

The third factor is called presence on website, which consists of two variables of activity and time on website. Table 3 demonstrates the details of our analysis where Cronbach alpha (1951) is 81\%.

Table 3

Factor analysis for presence on website of advertisement

\begin{tabular}{lllll}
\hline Option & Factor weight & Eigen value & \% of variance & Accumulated \\
\hline Presence on website & 0.838 & & & \\
Activity on website & 0.827 & 2.367 & 5.637 & 22.050 \\
\hline
\end{tabular}

\subsection{Persuasions}

The fourth factor is called persuasions, which consists of two variables of advertisement persuasions and animation. Table 4 shows the details of our analysis where Cronbach alpha (1951) is 60\%.

Table 4

Factor analysis for presence on website of advertisement

\begin{tabular}{lllll}
\hline Option & Factor weight & Eigen value & \% of variance & Accumulated \\
\hline Presence on website & 0.757 & & & \\
Activity on website & 0.725 & 2.277 & 5.422 & 27.472 \\
\hline
\end{tabular}

\subsection{Social factor}

The fifth factor is social factor, which consists of four variables of religion, education, user friendly and logo. Table 5 shows the details of our analysis where Cronbach alpha (1951) is 57\%.

Table 5

Factor analysis for social factors of advertisement

\begin{tabular}{lllll}
\hline Option & Factor weight & Eigen value & \% of variance & Accumulated \\
\hline Religion & 0.791 & & & \\
Education & 0.739 & 1.972 & 4.695 & 32.168 \\
User friendly & 0.404 & & & \\
Logo & 0.359 & & & \\
\hline
\end{tabular}

\subsection{Attractiveness factor}

The sixth factor is attractiveness, which consists of three variables of physical, attractiveness and sexual attractiveness. Table 6 shows the details of our analysis where Cronbach alpha (1951) is 58\%.

\section{Table 6}

Factor analysis for attractiveness factors of advertisement

\begin{tabular}{lllll}
\hline Option & Factor weight & Eigen value & \% of variance & Accumulated \\
\hline Physical attractiveness & 0.773 & & & \\
Attractiveness & 0.741 & 1.891 & 4.501 & 36.669 \\
Sexual attractiveness & 0.528 & & & \\
\hline
\end{tabular}




\subsection{Contacts people factor}

The seventh factor is contacts people, which consists of three variables of compatibility of advertisement, Conflicts / expectations and Usability. Table 7 shows the details of our analysis where Cronbach alpha (1951) is 58\%.

\section{Table 7}

Factor analysis for contact people factors of advertisement

\begin{tabular}{|c|c|c|c|c|}
\hline Option & Factor weight & $\begin{array}{l}\text { Eigen } \\
\text { value }\end{array}$ & $\%$ of variance & Accumulated \\
\hline $\begin{array}{l}\text { Compatibility } \\
\text { advertisement }\end{array}$ & 0.753 & & & \\
\hline Conflicts / expectations & 0.681 & 1.719 & 4.094 & 40.763 \\
\hline Usability & 0.447 & & & \\
\hline
\end{tabular}

\subsection{Coding factor}

The eighth factor is coding, which consists of two variables of coding and typical advertisement. Table 8 shows the details of our analysis where Cronbach alpha (1951) is 61\%.

\section{Table 8}

Factor analysis for coding factors of advertisement

\begin{tabular}{lllll}
\hline Option & Factor weight & Eigen value & \% of variance & Accumulated \\
\hline Coding message & 0.781 & & & \\
Typical message & 0.746 & 1.653 & 3.935 & 44.698 \\
\hline
\end{tabular}

\subsection{Technical attributes factor}

The ninth factor is technical attributes, which consists of four variables of banner size, text length, acknowledgment and number of clicks. Table 9 shows the details of our analysis where Cronbach alpha (1951) is $41 \%$.

Table 9

Factor analysis for technical attributes factors of advertisement

\begin{tabular}{lllll}
\hline Option & Factor weight & $\begin{array}{c}\text { Eigen } \\
\text { value }\end{array}$ & \% of variance & Accumulated \\
\hline Banner size & 0.631 & & & \\
Text length & 0.609 & 1.465 & 3.489 & 48.187 \\
Acknowledgment & 0.435 & & & \\
Number of clicks & 0.380 & & & \\
\hline
\end{tabular}

\subsection{Depth of advertisement factor}

The tenth factor is depth of advertisement, which consists of three variables of customer, comparative advertisement and effectiveness. Table 10 shows the details of our analysis where Cronbach alpha (1951) is $48 \%$. 
Table 10

Factor analysis for depth of advertisement factors of advertisement

\begin{tabular}{lllll}
\hline Option & Factor weight & $\begin{array}{l}\text { Eigen } \\
\text { value }\end{array}$ & \% of variance & Accumulated \\
\hline Customer & 0.721 & & & \\
Comparative advertisement & 0.603 & 1.417 & 3.373 & 51.560 \\
Effectiveness & 0.513 & & & \\
\hline
\end{tabular}

\subsection{Technical attractiveness of advertisement factor}

The eleventh factor is technical attractiveness of advertisement, which consists of three variables of number of frames, logical attractiveness and emotional attractiveness. Table 11 shows the details of our analysis where Cronbach alpha (1951) is 57\%.

Table 11

Factor analysis for technical attractiveness of advertisement

\begin{tabular}{lllll}
\hline Option & Factor weight & $\begin{array}{l}\text { Eigen } \\
\text { value }\end{array}$ & \% of variance & Accumulated \\
\hline Number of frames & 0.698 & & & \\
Logical attractiveness & 0.675 & 1.334 & 3.176 & 54.736 \\
\hline Emotional attractiveness & 0.526 & & & \\
\hline
\end{tabular}

\subsection{Text format of advertisement factor}

The twelfth factor is technical attractiveness of advertisement, which consists of three variables of number of text, organization of message and complexity of text. Table 12 shows the details of our analysis where Cronbach alpha (1951) is $96 \%$.

Table 12

Factor analysis for technical attractiveness of advertisement

\begin{tabular}{lllll}
\hline Option & Factor weight & $\begin{array}{l}\text { Eigen } \\
\text { value }\end{array}$ & \% of variance & Accumulated \\
\hline Number of frames & 0.757 & & & \\
Logical attractiveness & 0.578 & 1.273 & 3.032 & 57.765 \\
Emotional attractiveness & -0.426 & & & \\
\hline
\end{tabular}

\subsection{Strategy of advertisement factor}

This factor is strategy of advertisement, which consists of two variables of entertainment and persuasive strategies. Table 13 shows the details of our analysis where Cronbach alpha (1951) is $52 \%$.

Table 13

Factor analysis for technical attractiveness of advertisement

\begin{tabular}{lllll}
\hline Option & Factor weight & $\begin{array}{l}\text { Eigen } \\
\text { value }\end{array}$ & \% of variance & Accumulated \\
\hline Entertainment strategy & 0.653 & & &
\end{tabular}




\subsection{Distinguish factor}

Distinguish factor consists of two variables of distinguished and change of picture. Table 14 shows the details of our analysis where Cronbach alpha (1951) is 34\%.

Table 14

Factor analysis for distinguished factor

\begin{tabular}{lllll}
\hline Option & Factor weight & $\begin{array}{l}\text { Eigen } \\
\text { value }\end{array}$ & \% of variance & Accumulated \\
\hline $\begin{array}{l}\text { Distinguished } \\
\text { Change of picture. }\end{array}$ & 0.814 & & & \\
\hline
\end{tabular}

\subsection{Effective factor}

Effective factor consists of two variables of volume of information and entertainment. Table 15 shows the details of our analysis where Cronbach alpha (1951) is 44\%.

\section{Table 15}

Factor analysis for effective factor

\begin{tabular}{lllll}
\hline Option & Factor weight & $\begin{array}{l}\text { Eigen } \\
\text { value }\end{array}$ & \% of variance & Accumulated \\
\hline $\begin{array}{l}\text { Distinguished } \\
\text { Change of picture. }\end{array}$ & -0.699 & & & \\
\hline
\end{tabular}

In summary, we can conclude that there are 15 factors influencing a multimedia advertisement. Each factor consists of different components, which are between two to four and the relative importance of each factor is demonstrated, separately.

\section{Conclusion}

In this paper, we have presented a Factor analysis to investigate various important factors involved in multimedia advertisement. The proposed study of this paper selected travel agencies who worked in capital city of Iran, Tehran. A questionnaire was designed and distributed among them and the gathered information were first analyzed and the unsuitable questions were removed and the remaining questions were analyzed using Factor analysis. We hope the results of this study could be used for better promoting travel agencies for other real-world case studies.

\section{References}

Baltas, G. (2003). Determinants of internet advertising effectiveness: an empirical study. International Journal of Market Research, 45(4), 505-513.

Brace, N., Kemp, R., \& Snelgar,R. (2006). SPSS for psychologists: A guide to data analysis using SPSS for windows, $3^{\text {rd }}$ edition, PALGRAVE MACMILLAN.

Brett, M.A.S., Bhimym A. C., Tom, A. (2002). Infomercials and advertising effectiveness: an empirical study. Journal of Consumer Marketing, 19(6), 468- 480.

Chuang, T.T., \& Chong, P. P. (2004). Searching advertising placement in cyberspace. Industrial Management \& Data Systems, 104(2), 144-148. 
Chowdhury, R.M.M.I., Olsen, G.D., \& Pracejus, J.W. (2011). How many pictures should your print ad have?. Journal of Business Research, 64(1), 3-6.

Cronbach, L. J. (1951). Coefficient alpha and the internal structure of tests. Psychometrika, 16(3), 297-334.

Codaccioni, C., \& Tafani, É. (2011). Advertising effectiveness as a function of numerical support: From majority compliance to minority conversion. European Review of Applied Psychology, 61(2), 77-87.

Hawkins, D. (2007). Consumer Behavior: Building Marketing Strategy, $9^{\text {th }}$ ed. TaTa McGraw Hill.

James, W.L., \& Kover, A. (1992). Do overall attitudes toward advertising affect involvement with specific advertisements?', Journal of Advertising Research, 32(5), 78-83.

Jeon, J.O., \& Beatty, S.E. (2002). Comparative advertising effectiveness in different national cultures. Journal of Business Research, 55(11), 907-913.

Liu, F., Cheng, H., \& Li, J. (2009). Consumer responses to sex appeal advertising : a cross-cultural study. International Marketing Review, 26(4/5) , 501-520.

Likert, R. (1932). A Technique for the Measurement of Attitudes. Archives of Psychology, 140, 1-55.

Lee-Wingate, S. N., \& Xie, Y. (2010). Consumer perceptions of product-claim versus help-seeking direct-to-consumer advertising. International Journal of Pharmaceutical and Healthcare Marketing, 4(3), $232-246$.

McKay-Nesbitt, J., Manchanda, R.V., Smith, M. C., \& Huhmann, B. A. (2011). Effects of age, need for cognition, and affective intensity on advertising effectiveness. Journal of Business Research, 64(1), 12-17.

Mehta, A. (2000) Advertising attitudes and advertising effectiveness. Journal of Advertising Research, may/june , 67-72.

Phau, I., \& Lum, L. (2000). Effects of physical attractiveness in the evaluation of print advertisements. Asia Pacific Journal of Marketing and Logistics,12, 41-59.

Patsioura, F., Vlachopoulou, M., \& Manthou, V. (2009). A new advertising effectiveness model for corporate advertising web sites: a relationship marketing approach. Benchmarking: An International Journal, 16(3), 372-386.

Phau, I., \& Teah, M. (2009). Young consumer's motives for using sms and perceptions towards sms advertising. Direct Marketing: An International Journal, 3(2), 97-108.

Sirvastava, R.K. (2010). Effectiveness of global advertisement on culture of India: an emerging market. International Journal of Emerging Markets, 5(1), 102-113.

Shavitt, S. Lowery, P., \& Haefner, J. (1998). Public attitudes toward advertising: more favorable than you might think. Journal of Advertising Research, 38(4), 7-22.

Wang, A. (2009). Cross-channel integration of advertising: dose personal involvement matter?. Management Research News, 32(9), 858-873.

$\mathrm{Wu}$, S. (2001). An experimental study on the relationship between consumer involvement and advertising effectiveness. Asia Pacific Journal of Marketing and Logistics, 13(1), 43-56. 